Original Research Paper

\title{
Fiber Laser Beam Welding Between Niobium and Titanium
}

\author{
Rafael Humberto de Mota Siqueira, Isabela Atilio, Caroline Cristine de Andrade Ferreira, \\ Sheila Medeiros de Carvalho and Milton Sergio Fernandes de Lima
}

Photonics Division, Institute for Advanced Studies, 12.228-001 São Jose dos Campos, Brazil

\author{
Article history \\ Received: 28-01-2020 \\ Revised: 13-02-2020 \\ Accepted: 07-03-2020 \\ Corresponding Author: \\ Milton Sergio Fernandes de \\ Lima \\ Photonics Division, Institute \\ for Advanced Studies, \\ 12.228-001 São Jose dos \\ Campos, Brazil \\ Email: msflima@gmail.com
}

\begin{abstract}
Niobium and titanium are difficult to weld because of many factors, such as their tendency to oxidize and burn and the relatively high melting temperatures. Here, fiber laser beam welding has been proposed to weld $\mathrm{Nb}$ and $\mathrm{Ti}$ sheets in overlap geometry. In the current research, one millimeter thick CP-Ti was placed at the top and a $3 \mathrm{~mm}$ pure $\mathrm{Nb}$ stay underneath. The laser parameters were power between 1000 and $1400 \mathrm{~W}$ and speed between 20 and $60 \mathrm{~mm} / \mathrm{s}$, with the focus on the upper surface (beam diameter of $0.1 \mathrm{~mm}$ ). The fusion depth varied, but the average value was $1.7 \pm 0.3 \mathrm{~mm}$, i.e. about $0.7 \mathrm{~mm}$ into the $\mathrm{Nb}$-phase. The microstructure was characterized by a partial dissolution between the $\mathrm{Nb}$-rich and Ti-rich regions all over the $\beta(\mathrm{Nb}, \mathrm{Ti})$ solid solution at high temperatures. The microconstituents presents slightly different hardnesses from 130 to $180 \mathrm{HV}_{0.05}$ depending on the region. The welds are defect free, even at the interface between the plates and around the phase modulations. These features indicate that the laser beam welding of Ti-Nb alloys could be a valuable technique for the fabrication of aerospace components.
\end{abstract}

Keywords: Niobium, Titanium, Laser Beam Welding, Aerospace Materials

\section{Introduction}

Niobium and titanium are common materials in aerospace industries in application such as rocket boosters and hot sections of the turbines (Santos et al, 2004). Additionally, $\mathrm{Nb}$-Ti alloys have proven to be useful as superconductor components (Meingast and Larbalestier, 1989) and potential base alloys for high performance batteries (Dai et al, 2015).

These elements are difficult to melt because of many factors, such as their tendency to oxidize and burn and the relatively high melting temperature difference between $\mathrm{Nb}$ and $\mathrm{Ti}, 2477^{\circ} \mathrm{C}$ and $1668^{\circ} \mathrm{C}$, respectively. Indeed, the chemical homogenization of even small pellets of such refractory metals in electrical furnace is a long and delicate process (Gordon and Hurford, 1953).

To overcome these challenges, laser beam welding has been proposed to weld $\mathrm{Nb}$ and $\mathrm{Ti}$ in overlap geometry to simulate a discrete mixture of phases for some applications.

Torkamany et al. (2016) studied pulsed laser welding between niobium and Ti-6Al-4V titanium alloy from a pool shape point of view. These authors reported a lack of penetration in $\mathrm{Nb}$ due to the absence of keyhole mode during Nd:YAG-type laser interaction. These findings corroborate previous publications of the same authors
(Torkamany et al., 2014) about pulsed laser welds of these materials. According to the authors the welds presented defects and break easily at the $\mathrm{Nb}$ joint side.

Hon et al. (2003) produced Nb-Ti alloys for implants, considering the relatively low elastic modulus of the alloy compared to conventional material for prosthesis Ti-6Al-4V. The authors produced alloys ranging from $\mathrm{Ti}-14 \% \mathrm{Nb}$ to $\mathrm{Ti}-40 \% \mathrm{Nb}$ melted in a vacuum crucible following numerous remelts and then hot rolling. The microstructures presented a mixture between $\alpha$-phase (hexagonal crystallographic structure) and $\beta$-phase (body-centered structure), from $14 \%$ to $34 \% \mathrm{Nb}$ and were fully $\beta$ between 34 and $40 \% \mathrm{Nb}$,

Following these reports, it could be interesting to investigate the weldability between $\mathrm{Ti}$ and $\mathrm{Nb}$ using new laser technologies. Consequently, this work aims to investigate the microstructure and hardness of superposed $\mathrm{Ti}-\mathrm{Nb}$ sheets using a fiber laser.

\section{Experimental}

The start materials were $1 \mathrm{~mm}$ thick commercial purity titanium (CP-Ti) and $3 \mathrm{~mm}$ thick pure niobium sheets. Both materials were provided as hot rolled and annealed blanks. The blanks were ground with SiC600 paper and then cleaned using de-ionized water and 
ethanol. In the current setup, superposed welds with a Ti sheet at the top and a $\mathrm{Nb}$ underneath were done.

The laser workstation is a YLR-2000 IPG Photonics fiber laser with a maximum power output of $2000 \mathrm{~W}$. The sample moving is given by a CNC table. The sheets were clamped using a special tool to avoid large gaps. The gas shield consisted of a tube coaxial to the laser beam allowing a stable flow of pure argon around the melt pool. The Ar flux was set at $12 \mathrm{l} / \mathrm{min}$.

The laser parameters were power between 1000 and $1400 \mathrm{~W}$ and speed between 20 and $60 \mathrm{~mm} / \mathrm{s}$, with the focus on the upper surface (beam diameter of $0.1 \mathrm{~mm}$ ). These ranges of parameters were chosen as representative of other experiments. Table 1 presents the experimental parameters for the welds. The Heat Input (HI) was calculated as the ratio between power (P) and velocity (v).

After welded, the samples were cut using a diamond saw, ground and polished in a sequence of diamond colloidal suspensions up to the final polishing using a $0.5 \mu \mathrm{m}$ alumina solution. The cross sections of the welds were etched using Kroll's reagent $(92 \mathrm{~mL}$ distilled water, $6 \mathrm{~mL}$ nitric acid and $2 \mathrm{~mL}$ hydrofluoric acid) which was effective to darkening the Ti-side. The optical microscopy was a Imager2M Zeiss model equipped with a digital camera.

The weld surfaces were analyzed by X-ray diffractometry using a Rigaku Ultima IV equipment with a $\mathrm{Cu}$ anode tube.

The hardness profile was obtained using a Vickers microhardness tester model FM-800 from FutureTech. The load was fixed at $50 \mathrm{gf}\left(\mathrm{HV}_{0.05}\right)$ and the dwell time was 10 seconds. Each indentation distances $100 \mu \mathrm{m}$ from the neighbors.

\section{Results and Discussion}

Figure 1 presents the general view of the weld surface (titanium side). As can be seen the, surface aspect is silver bright with a little oxidation when the laser beam strikes the surface at the begining (left side of beads B and C) due to boarder effects. The weld width (w) increased linearly with increasing $\mathrm{HI}$ (Table 1$)$ as given by the equation $\mathrm{w}=$ $0.0354 \times \mathrm{HI}+0.3908\left(\mathrm{R}^{2}=0.97\right)$.

The fusion depth (d) also varied, but without an apparent relation on $\mathrm{HI}$ (Fig. 2). The d-average value was $1.7 \pm 0.3 \mathrm{~mm}$, i.e., about $0.7 \mathrm{~mm}$ into the $\mathrm{Nb}$-phase. Considering the weld bead profiles and the densities of each element, the average composition of the melt (in mass) would be Ti-13\% Nb. Figure 2 also shows unetched cross sections of the welds with dark gray stains as $\mathrm{Nb}$ rich regions and light gray as Ti-rich regions. One could see the homogenization was partial even at high HI (low velocities) and the stoichiometric balance $\mathrm{Ti}-13 \% \mathrm{Nb}$ does not apply. The reasons for this are the very different pool shapes, finer in the $\mathrm{Nb}$ sheet due to the high melting temperature and the differences in densities which rends difficult depth convective currents.

Table 1: Experimental parameters for the laser welds

\begin{tabular}{llll}
\hline Code & v $(\mathrm{mm} / \mathrm{s})$ & P $(\mathrm{W})$ & HI $(\mathrm{J} / \mathrm{mm})$ \\
\hline A & 60 & 1000 & 16.7 \\
B & 60 & 1200 & 20.0 \\
C & 60 & 1400 & 23.3 \\
D & 40 & 1000 & 25.0 \\
E & 40 & 1200 & 30.0 \\
F & 20 & 1000 & 50.0 \\
\hline
\end{tabular}

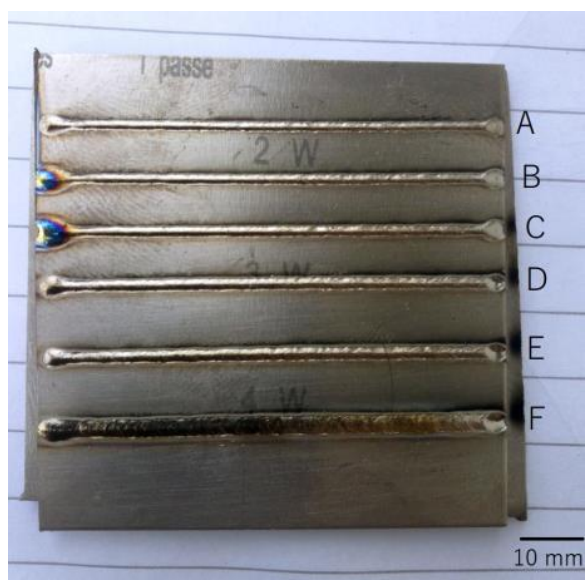

Fig. 1: Surface view of the component after the welds

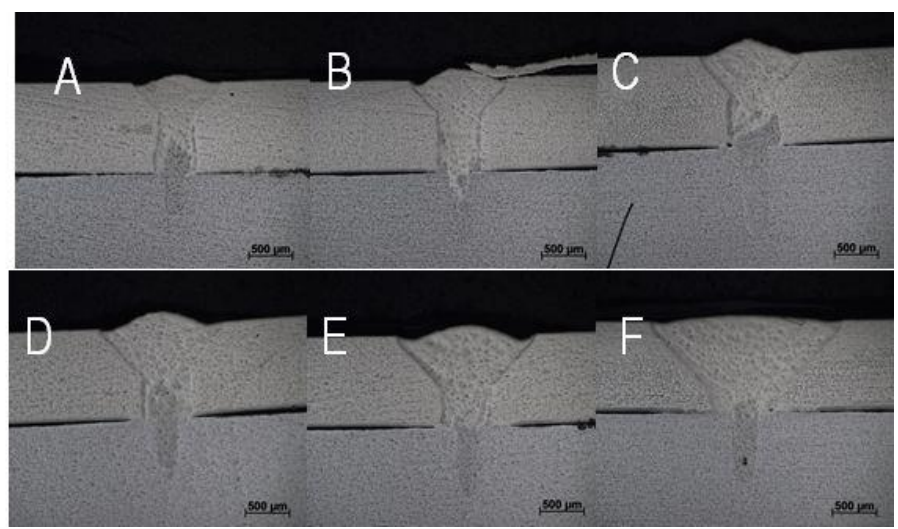

Fig. 2: Cross-section images of the welds 


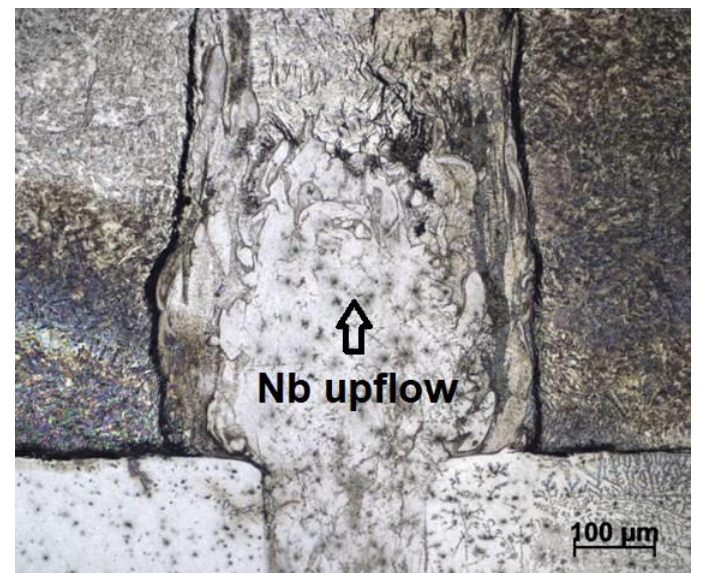

(A)

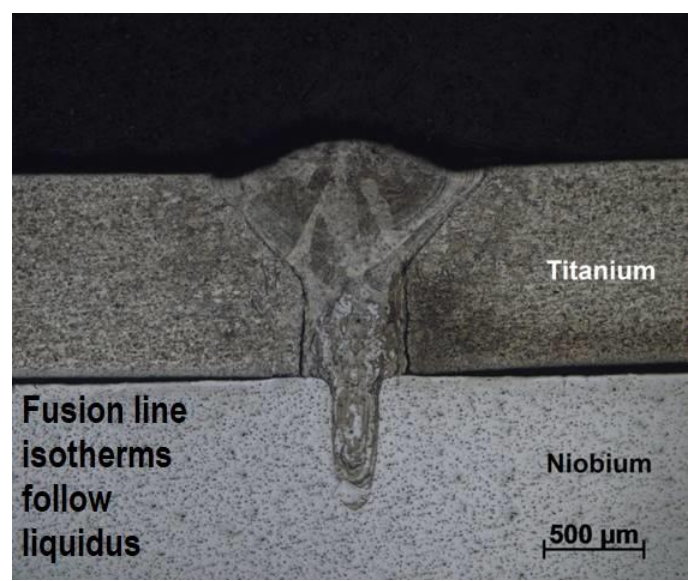

(C)

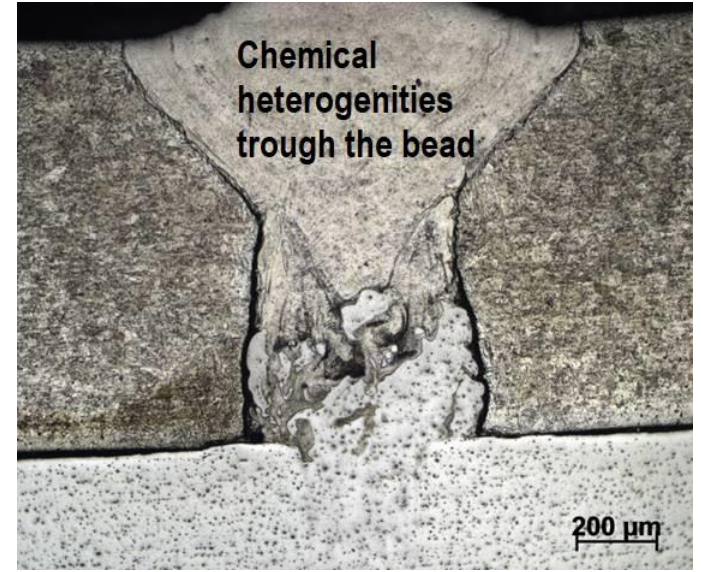

(B)

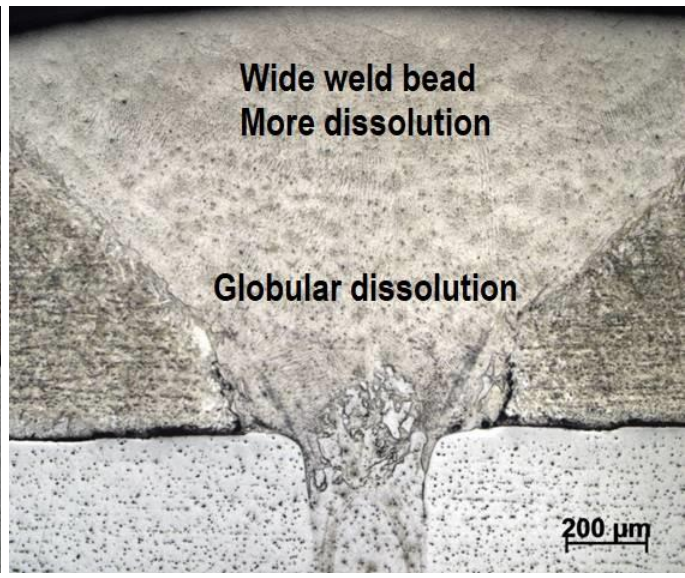

(D)

Fig. 3: Microstructure of selected regions in the welds. The letters refer to Table 1

The microstructure was characterized by a partial dissolution between the Nb-rich and Ti-rich regions all over the $\beta(\mathrm{Nb}, \mathrm{Ti})$ solid solution at high temperatures. The $\beta$ is retained in the $\mathrm{Nb}$-rich regions, although transforms to $\alpha$ ' martensite in Ti-rich regions. Figure 3 presents a series of micrographs of the polished and etched cross-sectional joints. A close look at the interface between the sheets in condition A (Fig. 3A) reveals the $\mathrm{Nb}$ up flow as a result of the keyhole high temperature. This $\mathrm{Nb}$ up flow causes chemical heterogeneities through the weld as can can be seen in condition C (Fig. 3B). Figure 3C (condition C) shows that one possible reason for the unbalanced chemical composition is the melt width following liquidus isotherms in each material. This is the reason why it is noted a much finer fusion zone in the $\mathrm{Nb}$ sheet. When the heat input is sufficiently high, like condition $\mathrm{D}$, the weld bead is sufficiently wide to dissolve the $\mathrm{Nb}$ globules coming the sheet underneath (Fig. 3D).

Figure 4 presents an X-ray diffractogram of the weld surfaces for all conditions. The diffractogram lines superpose in all conditions excepting condition $\mathrm{F}$, marked blue in Fig. 4. The dilution of $\mathrm{Nb}$ in titanium at high heat input induced a distortion of the hexagonal cell of the $\alpha$-phase as noted in the spectra. However, niobium additions in titanium is not enough to induce retained $\beta$ phase as reported by Hon et al. (2003). According to Yang et al. (2018), the hexagonal distortion observed in the $\mathrm{F}$ condition (blue in Fig. 4) is due to the $\mathrm{Nb}$ solidsolution in the structure.

Figure 5 presents the Vickers hardness profile for each condition as a function of the distance from the upper surface (interface as a dashed line). These microconstituents presents slightly different hardness being around $180 \mathrm{HV}_{0.05}$ for $\mathrm{Ti}(\mathrm{Nb}) \alpha$-phase and $130 \mathrm{HV}_{0.05}$ for $\beta-\mathrm{Nb}$. The wide variation in the hardness values reflects the heterogeneity of $\mathrm{Nb}$ in $\mathrm{Ti}$ matrix. When the heat input is sufficiently high to increase homogenization, the $\mathrm{HV}$ curve variation is greatly reduced as can be seen in curve $\mathrm{F}$ in Fig. 5. In terms of mechanical behavior, it is preferable to obtain as low as possible changes in hardness to avoid stress concentrators. Therefore, the conditions $\mathrm{E}$ and $\mathrm{F}$, i.e., heat input of 30 and $50 \mathrm{~J} / \mathrm{mm}$, are particularly interesting. 


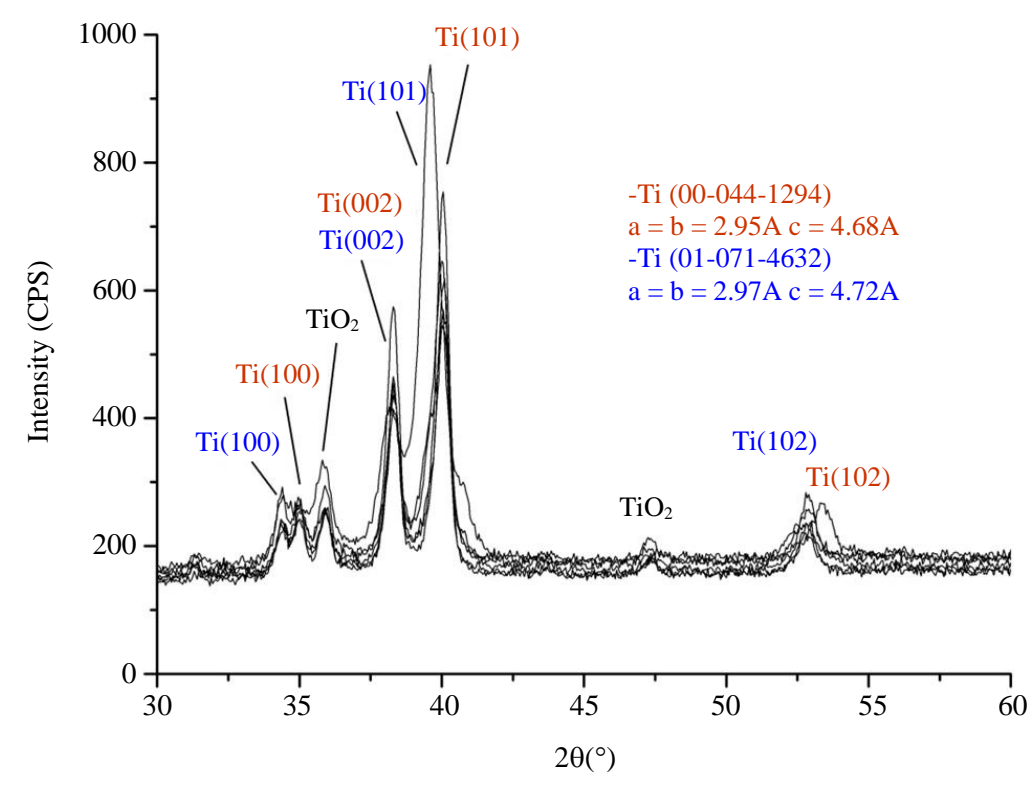

Fig. 4: X-ray diffractograms of the welds

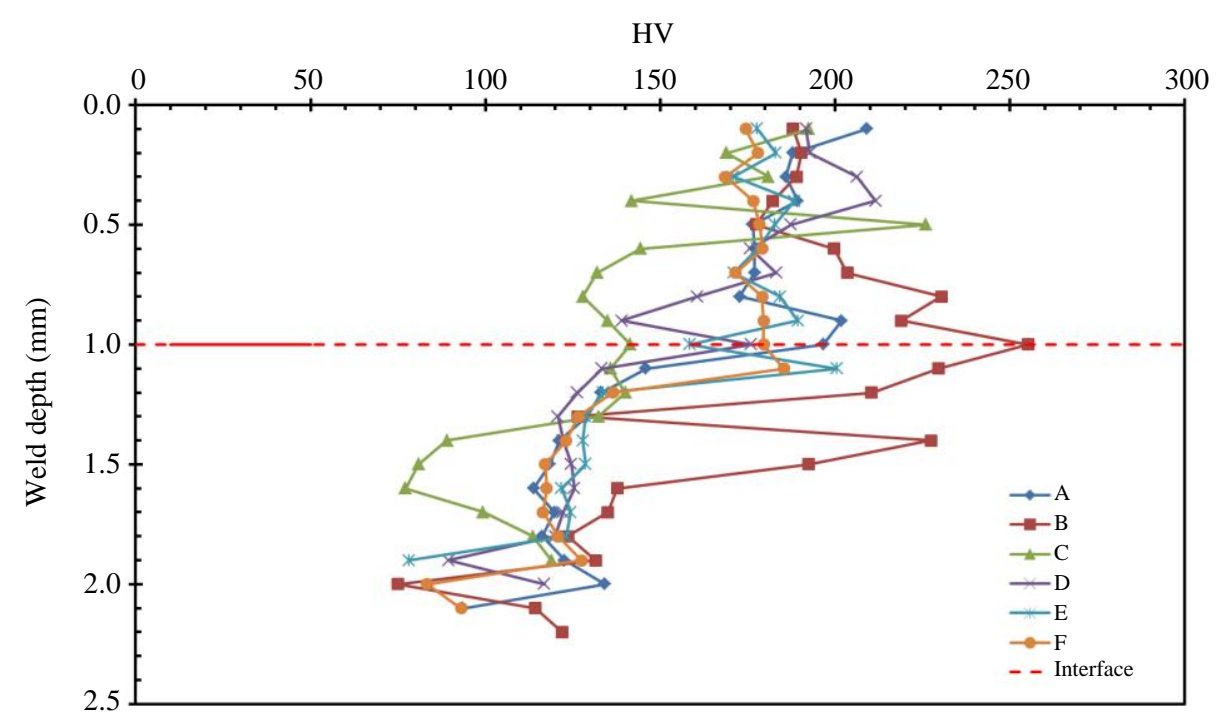

Fig. 5: Hardness profile of different conditions as a function of depth

\section{Conclusion}

The welds are defect free, even at the interface between the plates and around the phase modulations.

The laser power and speed of 1-1.4 $\mathrm{kW}$ and 20-60 $\mathrm{mm} / \mathrm{s}$ are sufficient to produce $1.7 \mathrm{~mm}$ depth welds.

The globular dissolution and mass flow around the keyhole seems to be significant for the homogenization of the weld bead.

When the heat input is $50 \mathrm{~J} / \mathrm{mm}$ structural changes occur in the X-ray diffractogram as an indication of $\mathrm{Nb}$ dissolution in Ti matrix.
The hardness profile seems a continuous decrease of $\mathrm{HV}$ from top ( $\mathrm{Ti})$ to bottom $(\mathrm{Nb})$, with some spikes in all conditions.

These features indicate that the laser beam welding of Ti-Nb alloys could be a valuable technique for the fabrication of $\mathrm{Ti}-\mathrm{Nb}$ aerospace components.

\section{Acknowledgment}

This research has been supported by Fundação de Amparo à Pesquisa do Estado de São Paulo (FAPESP) under grant number 2016/16683-8. 


\section{Author's Contributions}

Rafael Humberto de Mota Siqueira: Conceived and designed the analysis.

Isabela Atilio: Performed the laser experiments.

Caroline Cristine de Andrade Ferreira: Performed the microstructural analysis.

Sheila Medeiros de Carvalho: Performed the hardness analysis.

Milton Sergio Fernandes de Lima: Managed the research; Wrote the paper.

\section{Ethics}

The authors have declared no ethical issue of the publication of the present paper.

\section{References}

Dai, S., B. Guo, X.G. Sun and Z. Qiao, 2017. Nanoporous titanium niobium oxide and titanium tantalum oxide compositions and their use in anodes of lithium ion batteries. US Patent Office, Patent US 20150056514 A1, Filled 31/10/2017.

Gordon, R.B. and W.J. Hurford, 1953. Method of producing sound and homogeneous ingots. US Patent Office, Patent US US3072982A.

Hon, Y.H., J.Y. Wang and Y.N. Pan, 2003. Composition/phase structure and properties of titanium-niobium alloys. Mater. Trans., 44: 2384-2390. DOI: 10.2320/matertrans.44.2384
Meingast, C. and D.C. Larbalestier, 1989. Quantitative description of a very high critical current density $\mathrm{Nb}$-Ti superconductor during its final optimization strain. II. Flux pinning mechanisms. J. Applied Phys., 66: 5971-5983. DOI: 10.1063/1.343625

Santos, D., M. Pereira, V. Henriques and C. Cairo, 2004. Production of Ti-35Nb alloy by powder metallurgy for aerospace application. SAE Technical Paper 2004-01-3339.

Torkamany, M.J., F. Malek Ghaini and R. Poursalehi, 2014. Dissimilar pulsed Nd:YAG laser welding of pure niobium to $\mathrm{Ti}-6 \mathrm{Al}-4 \mathrm{~V}$. Mater. Design, 53: 915-920. DOI: 10.1016/j.matdes.2013.07.094

Torkamany, M.J., F. Malek Ghaini, R. Poursalehi and A.F.H. Kaplan, 2016. Combination of laser keyhole and conduction welding: Dissimilar laser welding of niobium and Ti-6Al-4V. Opt. Lasers Eng., 79: 9-15. DOI: 10.1016/j.optlaseng.2015.11.001

Yang, Y., P. Castany, E. Bertrand, M. Cornen and J.X. Lin et al., 2018. Stress release-induced interfacial twin boundary $\omega$ phase formation in a $\beta$ type Tibased single crystal displaying stress-induced $\alpha$ " martensitic transformation. Acta Mater., 149: 97-107. DOI: $10.1016 /$ j.actamat.2018.02.036 